\title{
PENGELOLAAN SUMBERDAYA IKAN KAKAP MERAH (Lutjanus spp.) DI PERAIRAN UTARA CIREBON, LAUT JAWA
}

\author{
RED SNAPPER (Lutjanus spp.) RESOURCES MANAGEMENT IN NORTHERN WATERS \\ OF CIREBON, JAVA SEA
}

\author{
Donald Noija1 ${ }^{1}$, Sulaeman Martasuganda², Bambang Murdiyanto², Am Azbas Taurusman ${ }^{2}$ \\ ${ }^{1}$ Program Studi Teknologi Perikanan Laut, Sekolah Pascasarjana \\ ${ }^{2}$ Program Studi Departemen Pemanfaatan Sumberdaya Perikanan \\ Fakultas Perikanan dan Ilmu Kelautan, Institut Pertanian Bogor \\ Korespondensi :ongki_noija@yahoo.co.id
}

\begin{abstract}
Red snapper (Lutjanus spp.) is one of the important commodity of demersal fish at the northern waters of Cirebon, Java Sea. The high degree of traditional fishing operations around the coastal area is expected to affect the availability of the fish stock. The Research results showed that there have been over fishing, it is caused by the large number of traditional fishing vessels at the coastal area, especially the persistence of the fishermen who use unfriendly fishing gear such as mini trawl. And then the red snapper which caught generally is young and never spawn or not yet mature. To solve that problem, it must arrange the amount of fishing vessels which can be operated at coastal area and it must law enforcement, and then to utilize the red snapper resources it advised to use the hook size larger than No. 10 and then install the rumpon at the new fishing ground which wider and farther. So the pressure to fishing ground of snapper can be reduced.
\end{abstract}

Keywords: Hierarchy Task. Analysis, safety fishermen, soma pajeko, work intensity

\begin{abstract}
ABSTRAK
Ikan kakap merah (Lutjanus spp.) merupakan salah satu sumberdaya ikan demersal komoditas penting di perairan utara Cirebon, Laut Jawa. Tingginya tingkat operasi penangkapan ikan tradisional di sekitar perairan pantai diduga mempengaruhi ketersediaan stok sumberdaya ikan tersebut. Hasil penelitian menunjukan bahwa telah terjadi over fishing yang disebabkan oleh banyaknya jumlah armada penangkapan ikan tradisional di sekitar perairan pantai, terlebih masih adanya nelayan yang menggunakan alat tangkap yang tidak ramah lingkungan seperti jaring arad (mini trawl) dan selain itu ikan kakap merah yang tertangkap, umumnya merupakan ikan muda yang belum matang gonad atau belum memijah. Sehubungan dengan hal tersebut perlu diatur jumlah armada penangkapan yang dapat beroperasi di perairan pantai dan penegakan peraturan serta pengelolaannya disarankan menggunakan alat tangkap yang selektif seperti menggunakan alat tangkap pancing dengan ukuran mata pancing yang lebih besar dari No. 10 dan pemasangan rumpon dasar diarahkan pada daerah fishing ground baru yang lebih luas dan jauh. Sehingga tekanan terhadap daerah penangkapan ikan kakap merah yang sekarang dapat dikurangi.
\end{abstract}

Kata kunci: Hierarchy Task. Analysis, intensitas kerja, keselamatan nelayan, soma pajeko

\section{PENDAHULUAN}

Kegiatan penangkapan ikan di wilayah perairan Indonesia sudah mendekati kondisi yang kritis, khususnya sumberdaya ikan demersal di WPP Laut Jawa atau WPP 712 (Kepmen KP nomor: KEP.45/MEN/2011). Ikan kakap merah (Lutjanus spp.) merupakan salah satu sumberdaya ikan demersal di Laut Jawa yang memiliki nilai ekonomis penting bagi nelayan Cirebon. Habitatnya berada di perairan pesisir pantai dan tertangkap dengan berbagai jenis alat penangkapan ikan (multi gears). Saat ini tingkat pemanfaatanya telah mengalami gejala over fishing diduga akibat tingginya tekanan penangkapan di wilayah perairan pesisir pantai, sehingga perlu diteliti aspek lain yang terkait.

Untuk mengantisipasi gejala over fishing tersebut, maka sumberdaya ikan di suatu perairan harus dikelola secara rasional, dengan memperhatikan aspek biologi, ekonomi, ekologi dan sosial (Widodo \& Suadi 2006) sehingga tercapai pengembangan perikanan kakap merah yang berkelanjutan. 


\section{METODE PENELITIAN}

Penelitian dilakukan selama 3 bulan (Januari-Maret 2014) di Cirebon (Gambar1), terhadap sampel ikan kakap merah (Lutjanus spp.) sebanyak 240 ekor (90 ekor $L$. malabaricus, 75 ekor L. russelli, dan 75 ekor L. johni $)$. Sampel ikan diperoleh secara acak dari hasil tangkapan nelayan Pangkalan Pendaratan Ikan (PPI) Cangkol Cirebon, Provinsi Jawa Barat dengan menggunakan alat tangkap pancing dengan ukuran mata pancing No. 8-10 yang dilengkapi dengan alat bantu pengumpul ikan berupa rumpon dasar.

Metode yang digunakan dalam penelitian ini adalah metode survei dengan menggali data dan informasi langsung dari lokasi penelitian di lapangan. Data yang dikumpulkan adalah data primer dan data sekunder. Secara umum jenis data yang dikumpulkan terdiri atas data biologi sumberdaya ikan, data potensi sumberdaya ikan, lingkungan perairan, dan sosial masyarakat nelayan.

Data biologi sumberdaya ikan, dianalisa menggunakan beberapa persamaan diantaranya :

1. Hubungan panjang total dengan berat menggunakan metode regresi linear (Effendi 2006) yaitu $\mathrm{W}=\mathrm{aL}^{\mathrm{b}}$, dimana $\mathrm{W}$ = berat ikan, $\mathrm{L}=$ panjang ikan, a dan $\mathrm{b}=$ konstanta. Nilai $\mathrm{b}$ yang diperoleh digunakan untuk menentukan pola pertumbuhan dengan kriteria: Jika b $=3$ (pertumbuhan bersifat isometrik), $\mathrm{v}>3$, maka pola pertumbuhan bersifat allometrik positif, $\mathrm{b}<3$ maka pola pertumbuhan bersifat allometrik negatif.

2. Tingkat Kematangan Gonad (TKG) yang dianalisa secara morfologis dan histologis (Effendi 1979).

3. Analisa panjang ikan pertama kali tertangkap menggunakan persamaan

Kertans (1985), yaitu: $\mathrm{Y}(\%)=\frac{100}{1+a \cdot e^{-b x}}$ , dimana $Y(\%)=$ proporsi tertahan pada setiap titik kelas panjang, $a=$ koefisien intersep, $b=$ slope, $e=$ eksponensial, dan $x=$ ukuran pertama kali tertangkap (Lc).

4. Fekunditas untuk penghitungan nilai fekunditas telur ikan dilakukan dengan metode campuran antara volumetri dan gravimetric (Effendie 1979), yaitu $F=$ GxV $\times X$ $G=$ Berat gonad (g), $V=$ Isi pengenceran (cc), $X=$ Jumlah telur tiap cc, dan $Q=$ Berat telur contoh (g).

5. Kebiasan Makan dilakukan dengan metode visual dan campuran antara volumetri dan gravimetric.

Data potensi sumberdaya ikan, dianalisa menggunakan beberapa persamaan diantaranya :

1. Standardisasi Upaya Tangkap. Menurut Gulland (1983) jika terdapat berbagai jenis alat tangkap yang digunakan di suatu wilayah peraian, dengan menggunakan persamaan $\mathrm{F}_{\text {standar }}=\sum F P I i x$ $F i)$, di mana $\mathrm{F}_{\text {standar }}=$ Alat tangkap standar, $F P I i=$ Fishing Power Indeks ke-i, dan Fi = Upaya penangkapan tahun ke-i jenis alat tangkap lain.

2. Metode Surplus Produksi. Menggunakan model linier yang disarankan oleh Schaefer yaitu $\mathrm{Y}(\mathrm{i})=a \cdot f(i)+b \cdot f(i)^{2}$, di mana $a=$ koefisien intersep, $b=$ slope, $\mathrm{Y}=$ hasil tangkapan dan $f=$ upaya penangkapan.

3. Tingkat pemanfaatan dan pengusahaan. Untuk tingkat pemanfaatan menggunakan persamaan $\frac{C_{i}}{M S Y} \times 100 \%$, dan tingkat pengusahaan $\frac{J_{i}}{f_{\text {opt }}} \mathrm{x}$ 100\%, di mana $C=$ hasil tangkapan, $F$ = upaya penangkapan, $M S Y=$ Maximum Sustainable Yield, dan $F_{o p t}=$ Upaya penangkapan optimum.

Data mengenai lingkungan perairan, dan sosial masyarakat nelayan diperoleh melalui teknik observasi dan wawancara.

\section{HASIL DAN PEMBAHASAN}

\section{Biologi sumberdaya ikan}

Hasil identifikasi terdapat 3 spesies ikan kakap merah (Lutjanus spp.) di perairan utara Cirebon-Laut Jawa, yaitu L. malabaricus (Bloch \& Schneider 1801), L.russelli (Bleeker 1849), dan L. johnii (Bloch 1792). Ikan kakap merah yang tertangkap memiliki ukuran panjang total (total length, TL) berkisar 196-666 mm, dengan panjang rata-rata $309.96 \mathrm{~mm}$. Pengamatan yang dilakukan pada frekuensi panjang ikan kakap merah menunjukkan kecenderung menyebar normal dengan modus frekuensi panjang ikan sebanyak 89 ekor Lutjanus spp. pada kelas interval 255 - 313 mm. Disajikan pada (Gambar 1)

Hasil analisa hubungan TL dengan berat untuk ke-3 spesies ikan kakap merah (Gambar 2) tersebut diperoleh persamaan yaitu L. malabaricus ( $\mathrm{W}=0.00005 \mathrm{~L} 2.799)$. L. russelli $(\mathrm{W}=0.00003 \mathrm{~L} 2.916)$, dan $L$. johnii $(\mathrm{W}=0.00005 \mathrm{~L} 2.816)$. Di mana ke tiga spesies Lutjanus tersebut menunjukan pola pertumbuhan allometrik negatif $(\mathrm{b}<3)$, yang 
artinya pola pertumbuhan panjang ikan kakap merah lebih cepat dari pertumbuhan berat tubuhnya.

Hasil penelitian rasio kelamin terhadap 24 ekor ikan kakap merah yang diambil secara acak berdasarkan keterwakilan dari masing-masing selang kelas total length dari tiap-tiap jenis ikan diperoleh rasio kelamin betina dan jantan $L$. malabaricus (2:1), $L$. russelli (1:1), dan L. johnii (3:2).

Hasil pengamatan secara visual dan histology telur terhadap sampel ikan tersebut didapatkan bahwa pada $L$. malabaricus dan $L$. johnii pada umumnya belum terliat keadaan matang gonad, sedangkan pada $L$. russelli sebagian telah ditemukan stadia matang gonad. Berdasarkan hasil perhitungan fekunditas telur yang dilakukan secara volumetri dan gravimetric pada sample ikan yang telah matang gonad diperoleh hasil bahwa $L$. russelli dengan panjang total 270 $\mathrm{mm}$, berat $354 \mathrm{gr}$ dan berat gonad 7.858 gr pada TKG-III terdapat fekunditas sebanyak 782.550 butir telur. Sedangkan pada panjang total $330 \mathrm{~mm}$, berat $587 \mathrm{gr}$ dan berat gonad 10.653 gr pada TKG-IV terdapat fekunditas sebanyak 1.150.695 butir telur.

Berdasarkan hasil tangkapan didapatkan nilai Length at first capture (Lc) alat tangkap pancing dengan ukuran mata pancing No. $8 \mathrm{~s} / \mathrm{d} 10$ pada $L$. malabaricus sebesar $309.38 \mathrm{~mm}$, pada $L$. russelli sebesar $267.66 \mathrm{~mm}$ (Gambar 3), dan pada L. johnii sebesar $294.61 \mathrm{~mm}$.

Berdasarkan hasil penelitian terhadap saluran percernaan sampel ikan kakap merah diperoleh informasi sebagaimana Tabel 1.

\section{Potensi sumberdaya ikan}

Hasil Tangkapan Utama (HTU) berupa ikan kakap merah di perairan utara Cirebon tertangkap dengan alat tangkap jaring arad, gillnet, pancing dan bubu. Dimana alat tangkap pancing yang dilengkapi dengan alat bantu pengumpul ikan berupa rumpon dasar menjadi alat tangkap yang paling penting (efektif dan efisien). Analisis potensi lestari dilakukan menggunakan metode surplus produksi dengan pedekatan model Schaefer diperoleh persamaan regresi linier CPUE = $8.582-0064 \mathrm{f}$, dengan $\mathrm{r}^{2}=0.896$.

Analisis potensi MSY merupakan salah satu standar biologis yang digunakan dalam pengelolaan dan konservasi sumberdaya perikanan yang berkelanjutan. Berdasarkan anallisa diperoleh informasi bahwa kondisi idealuntukdapat memanfaatkan sumberdaya ikan kakap merah secara optimum diperairan utara Cirebon yaitu menggunakan upaya standar (pancing) sebanyak 67 unit dengan proyeksi hasil tangkapan sebesar 287.76 ton/tahun (Gambar 4).

Tingkat pemanfaatan dan pengusahan terhadap upaya penangkapan dan hasil tangkapan pada tahun 2008 - 2012, diperoleh informasi tingkat pemanfaatan sumberdaya ikan kakap merah di perairan utara Cirebon cenderung over fishing dan telah melebihi nilai MSY yaitu pada tahun 2009 dengan tingkat pengusahaan sebesar $99.87 \%$ yang terdiri dari 205 unit arad, 1607 unit gillnet, 20 unit pancing dan 23 unit bubu (Gambar $5)$.

Penggunaan alat tangkap pancing dengan rumpon dasar dirasakan nelayan PPI Cangkol Kota Cirebon dapat meningkatkan ekonomi mereka karena HTU berupa kakap merah merupakan ikan komoditas ekspor dan bernilai ekonomis tinggi. Ikan kakap merah hasil tangkapan pancing tersebut dijual nelayan dalam bentuk segar (fresh) dengan harga Rp. 55.000/kg untuk L. malabaricus dan $L$. johnii, sedangkan $L$. russelli dijual dengan harga Rp. 45.000/kg. Pada saat musim penangkapan ikan pengoperasian kapal pancing yang dioperasikan dengan 2-4 orang ABK untuk one day fishing bisa memperoleh hasil tangkapan bernilai lebih dari Rp. 1.5 juta dengan biaya operasinal melaut sebesar Rp. 250.000,-. Selain itu tangkap pancing tersebut merupakan alat tangkap yang selektif dalam memperoleh HTU berupa ikan kakap merah (98 \%) dan dengan sedikit by-catch (2\%). By-catch umumnya masih memiliki nilai ekonomis yang cukup tinggi bagi nelayan Cirebon karena dijual dalam bentuk segar (Gambar 6). 


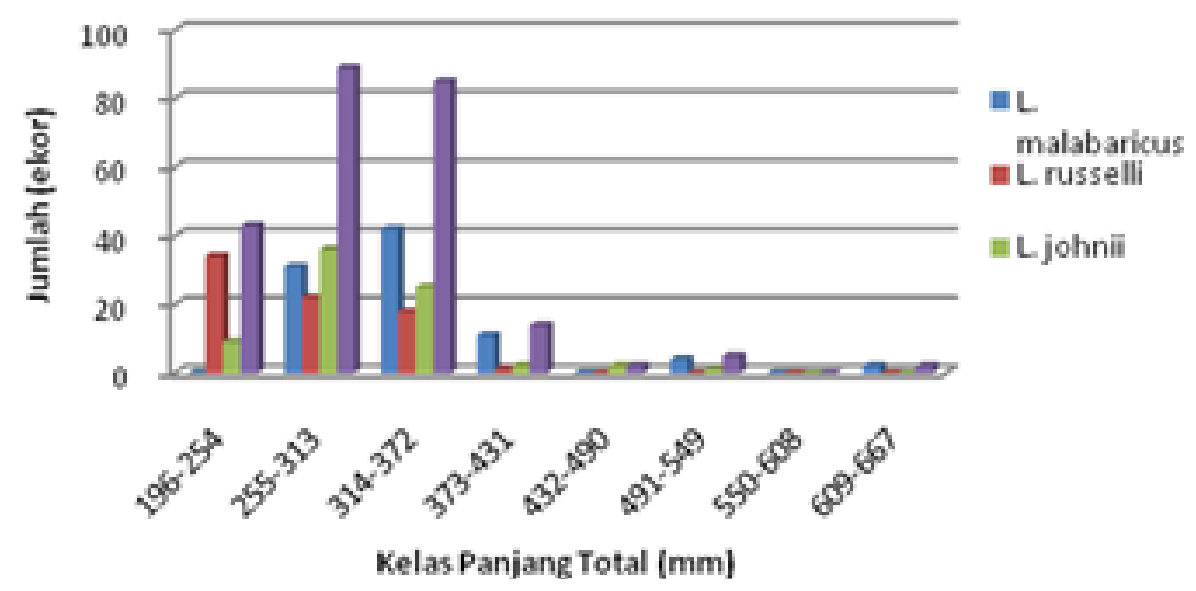

Gambar 1. Grafik selang kelas total length dengan frekuensi jumlah Lutjanus spp. di perairan utara Cirebon

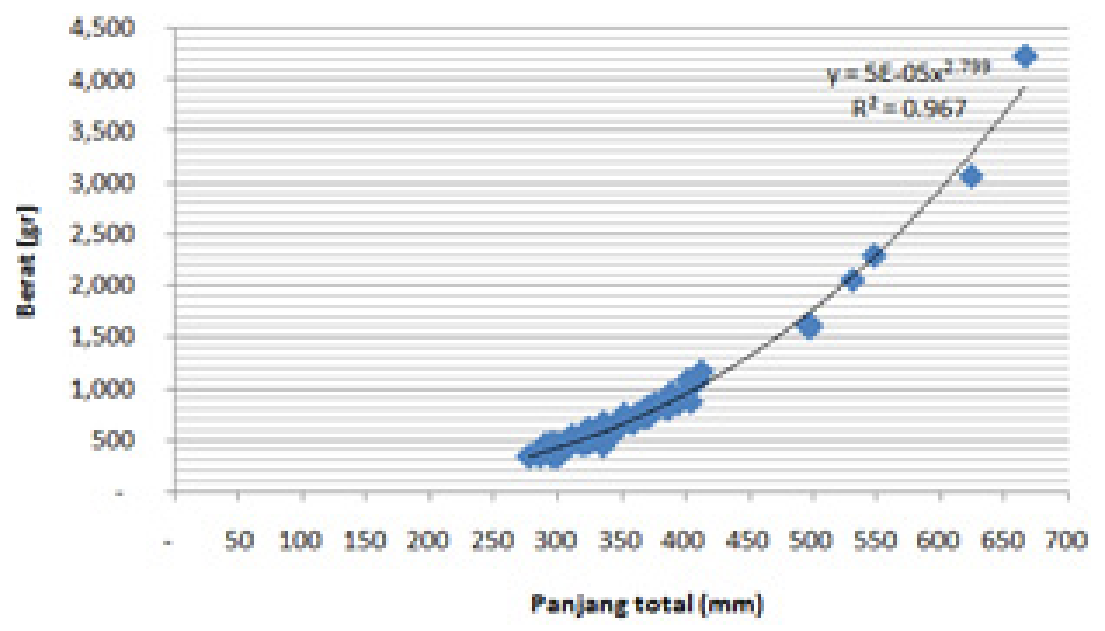

Gambar 2. Hubungan TL (mm) dengan berat (gr)

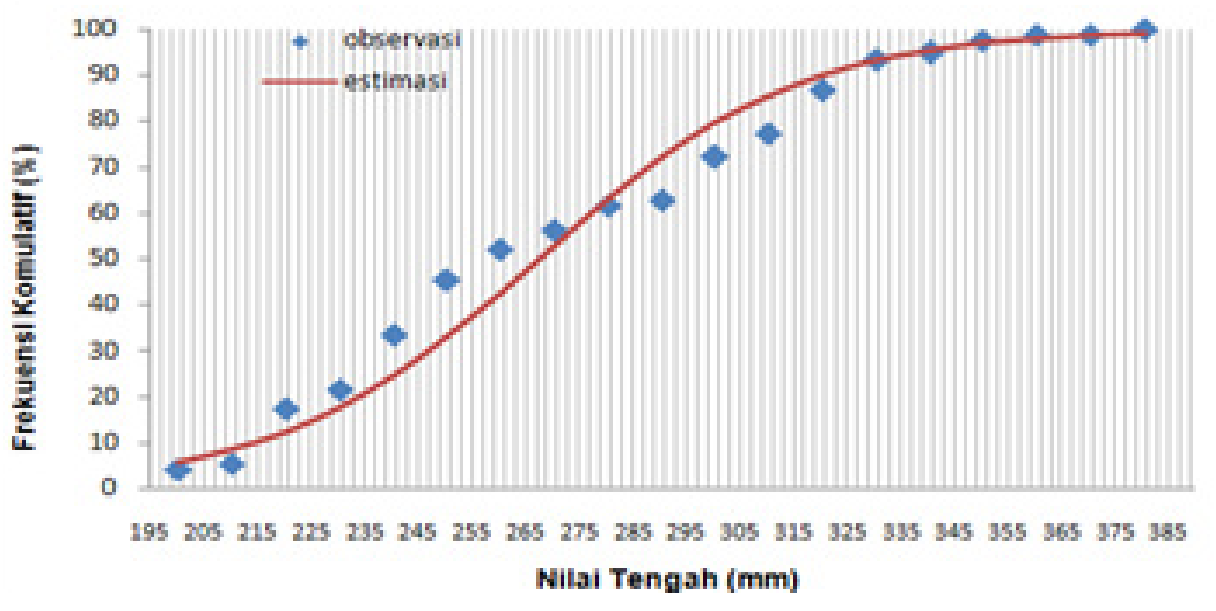

Gambar 3. Lc L.russelli di perairan utara Cirebon 
Tabel 1. Pengamatan makanan Lutjanus spp. pada saluran pencernaan

\begin{tabular}{|c|c|c|}
\hline Kakap Merah & Pengatan Visual & Pengamatan Lab. \\
\hline L. malabaricus & $\begin{array}{l}\text { ikan (rucah daging, tulang belakang/ } \\
\text { spin, sisik ikan), cumi, udang } \\
\text { (cruatacea), dll. }\end{array}$ & $\begin{array}{l}\text { crustacea (32.26\%), Calanus } \\
\text { sp. }(6.4 \%) \text {, Polychaeta sp. } \\
(1.33 \%) \text {, dll }\end{array}$ \\
\hline L. russelli & $\begin{array}{l}\text { ikan (rucah daging), udang (cruatacea), } \\
\text { dll }\end{array}$ & $\begin{array}{l}\text { udang (40\%), dan ikan jenis } \\
\text { Ambassis sp. }(40 \%) \text {, dll }\end{array}$ \\
\hline L. johnii & $\begin{array}{l}\text { ikan (rucah daging, tulang belakang/ } \\
\text { spin, sisik ikan), cumi, udang } \\
\text { (cruatacea), rajungan (Portunus } \\
\text { pelagicus), dll }\end{array}$ & $\begin{array}{l}\text { Crustacea sp. (33.33 \%), } \\
\text { rajungan }(6.67 \%) \text {, sisik ikan } \\
(6.67 \%)\end{array}$ \\
\hline
\end{tabular}

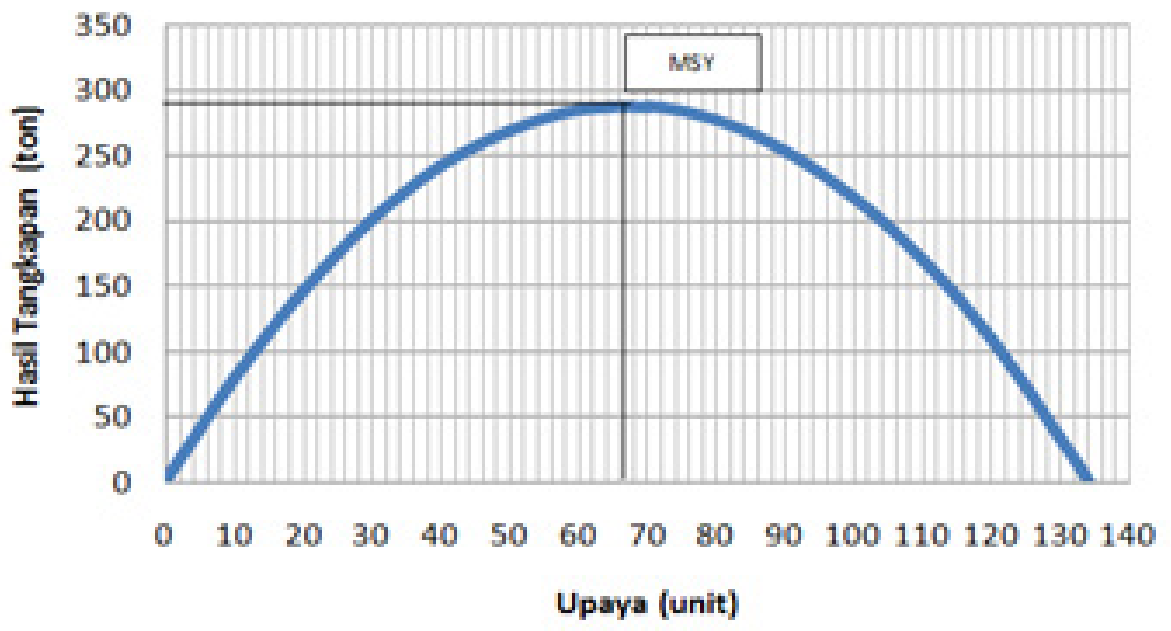

Gambar 4. Grafik hubungan antara upaya penangkapan dengan hasil tangkapan
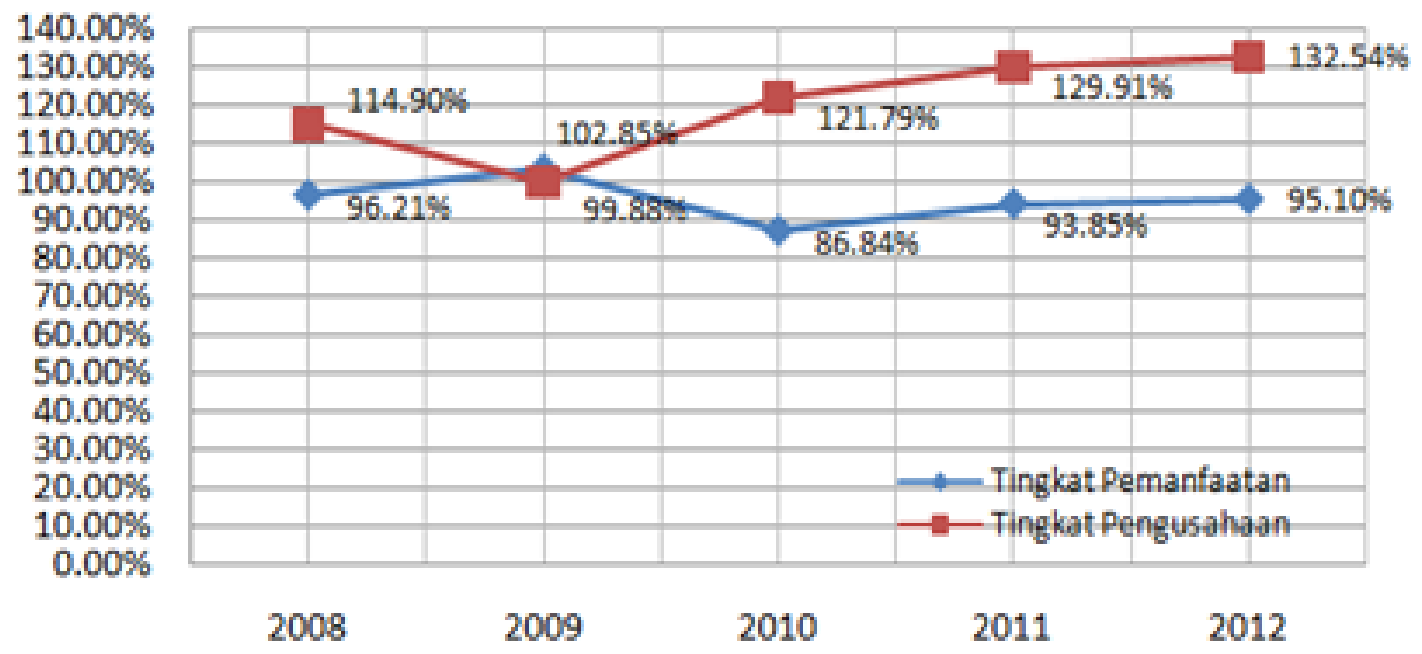

Gambar 5. Grafik tingkat pemanfaatan dan pengusahaan 


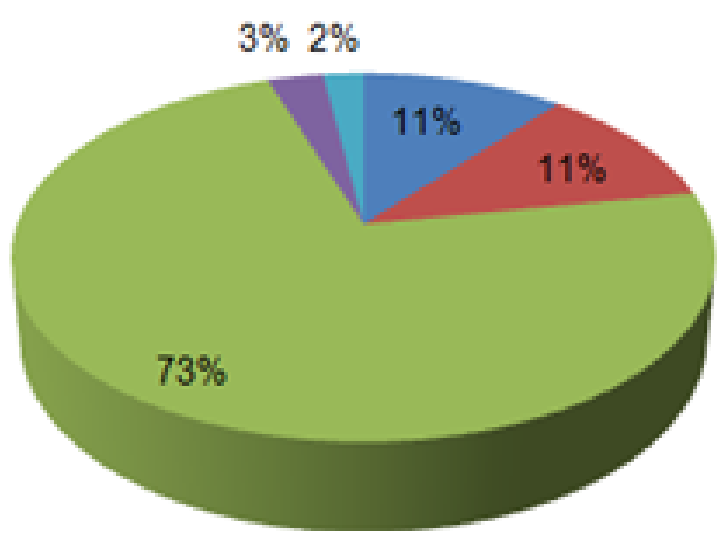

=Bambangan (Lutjanus malabaricus)

=Tanda-Tanda (Luțjanus malabaricus)

= Jenaha (Lutjanus johnii)

=Kerapu (Epinepherus spp.)

=Kuwe (Caranx spp.), Tigawajah (Johnius

Spp.), Kuro (Eleutheronema tetradactylum), kaci-

kadi (Plectorhinchus spp.), dII

Gambar 6. Persentasi komposisi hasil tangkapan

\section{Aspek lingkungan perairan}

Daerah penangkapan ikan fishing ground) kakap merah nelayan pancing PPI Cangkol merupakan daerah penangkapan ikan yang sudah pasti. Nelayan tersebut menangkapikan di sekitar lokasiterpasangnya rumpon dasar. Survei terhadap parameter lingkungan fishing ground ikan kakap merah diperoleh informasi bahwa lokasi fishing ground tersebut memiliki kedalaman 10-40 m, suhu permukaan laut berkisar $28-29.5{ }^{\circ} \mathrm{C}$, salinitas perairan berkisar 30-32 \% yang semakin tinggi pada perairan yang semakin jauh dari garis pantai, derajat keasaman berkisar 7-8, dan kecerahan perairan berkisar 5-5.5 $\mathrm{m}$ dengan semakin dalam tingkat kecerahannya pada perairan yang semakin jauh dari garis pantai.

\section{Aspek sosial}

Nelayan Cangkol awalnya merupakan nelayan jaring arad dan trammel net untuk menangkap udang dan ikan demersal. Tingginya tingkat eksploitasi disekitar perairan pantai mengakibatkan makin sulitnya mendapatkan ikan, sehingga seringkali mereka mengalami kerugian, yang diakibatkan oleh nilai hasil tangkapan ikan yang tidak dapat menutupi tingginya biaya operasional untuk melaut. Hasil tangkapan ikan kakap merah dirasakan mulai meningkat kembali setelah sebagian nelayan mulai menggunakan alat tangkap pancing yang dilengkapi dengan alat bantu pengumpul ikan berupa rumpon dasar.

Konflik antar nelayan pernah terjadi terkait dengan penggunaan ruang. Karena pemasangan rumpon awalnya berada di fishing ground sekitar pantai yang mengakibatkan rusaknya jaring arad dan gillnet ketika beroperasi. Kemudian untuk menghindari terjadinya konflik, nelayan pancing memindahkan fishing ground mereka ke arah yang lebih dalam dan jauh dari lokasi sebelumnya.

Dalam rangka pemanfaatan sumberdaya ikan yang lestari dan berkelanjutan, secara nasional telah di diatur oleh pemerintah dalam bentuk Peraturan Menteri Kelautan dan Perikanan Nomor: PER.02/MEN/2011. Selain itu terdapat juga kearifan lokal dalam masyarakat nelayan kota Cirebon, di mana ke dua peraaturan tersebut menyatakan bahwa trawl dan sejenisnya seperti arad dilarang untuk beroperasi WPP 712 (Laut Jawa).

\section{Pembahasan biologi sumberdaya ikan}

Menurut Djamal \& Marzuki (1992) di perairan sekitar Pulau Karimun Jawa dan Pulau Bawean teridentifikasi sebanyak 6 spesies ikan Lutjanus spp. yaitu L. johnii, $L$. sanguineus, $L$. sebae, L. malabaricus, L. vita, dan L. lineolatus. Sehubungan dengan hal tersebut dapat diinformasikan bahwa keragaman genus Lutjanus di perairan Utara Cirebon yang hanya berjumlah 3 spesies relatif sedikit dan berbeda dibandingkan daerah lain. Perbedaan tersebut diduga karena adanya perbedaan waktu identifikasi, alat tangkap yang digunakan dan habitatnya.

Hasil pengamatan kisaran panjang ikan 
kakap merah di perairan Labuan Banten (Imbalan 2013) diperoleh ukuran TL berkisar 225-570 mm dengan modus kelas interval 300$304 \mathrm{~mm}$. Hal tersebut menunjukkan kisaran panjang ikan kakap merah yang ada di perairan utara Cirebon tidak berbeda dengan yang ada di perairan Labuan Banten. Persamaan tersebut diduga karena kesamaan kondisi nutrisi perairan dan tingkat pemanfaatan oleh nelayan.

Analisis pola pertumbuhan pada ikan kakap merah di perairan Cirebon menunjukan pola pertumbuhan allometrik negatif, hal tersebut sesuai dengan populasi ikan kakap merah yang terdapat di beberapa daerah lain (Tabel 2).

Berdasarkan hasil analisa Lc ikan kakap merah yang tertangkap di perairan utara Cirebon terhadap Length at first maturity (Lm) ikan kakap merah yang terdapat di beberapa daerah (Tabel 3). Diperoleh informasi bahwa untuk L. malabaricus, L.russelli dan L. johnii secara umum Lc < Lm yang artinya ikan kakap merah di perairan utara Cirebon secara umum tertangkap merupakan ikan muda yang sebelum matang gonad atau belum melakukan pemijahan.

Namun berdasarkan pengamatan di lapangan, untuk ikan kakap merah jenis Lutjanus russelli dengan ukuran $\mathrm{TL}=270$ $\mathrm{mm}$ diperairan utara Cirebon sudah ditemui matang gonad. Hal tersebut menunjukan bahwa L.russelli di daerah tersebut lebih cepat matang gonad dibandingkan daerah lain. Maka kondisi tersebut menunjukkan, bahwa alat tangkap yang digunakan untuk penangkapan berpeluang untuk terjadinya growth over fishing dan recruitment over fishing di perairan tersebut. Menurut Wijaya et al. (2009), growth over fishing terjadi apabila hasil tangkapan didominasi oleh ikan-ikan kecil atau ikan muda, sedangkan recruitment over fishing atau tangkap lebih peremajaan terjadi apabila kegiatan perikanan tangkap banyak tertangkap ikan yang siap memijah (spawning stock).

Menurut Martinez \& Andrade (2003) makanan L. malabaricus terdiri dari ikan $(40 \%)$, small creustacean (30\%), decapode (30 $\%)$, makanan L. russelli terdiri dari ikan (15\%), small creustacean (15\%), decapode $(70 \%)$, makanan L. johnii terdiri dari ikan (45\%), small creustacean $(27.50 \%)$, decapode $(27.50 \%)$.

Sehubungan dengan hal tersebut, dapat di informasikan bahwa makanan utama ikan kakap merah berupa ikan, invertebrate bentic (udang, kepiting, dll), dan cumi, di mana jenis makanan tersebut merupakan jenis makanan yang banyak tersedia di perairan utara Cirebon, sehingga dapat disimpulkan bahwa perairan tersebut merupakan habitat tumbuh dan berkembang yang baik bagi Lutjanus spp.

Tabel 2. Hubungan panjang berat Lutjanus spp. di beberapa daerah

\begin{tabular}{llll}
\hline \multicolumn{1}{c}{ Area/ Perairan } & \multicolumn{1}{c}{ Lutjanus spp. } & \multicolumn{1}{c}{$\begin{array}{c}\text { Persamaan } \\
\text { (W=aLb) }\end{array}$} & $\begin{array}{l}\text { Penulis/ } \\
\text { Sumber }\end{array}$ \\
\hline Pantai Utara Australia & L. malabaricus & 0.0000234L2.879 & $\begin{array}{l}\text { O'Neill, M.F. } \\
\text { et.al (2009) }\end{array}$ \\
New Caledonian & L. russelli & 0.0166L2.978 & $\begin{array}{l}\text { Kulbicki, M.et. } \\
\text { al (2005) } \\
\end{array}$ \\
Kedah, Malaysia & L. johnii & 0.0218L 2.9195 & $\begin{array}{l}\text { Isa, M.M. et.al } \\
\text { (2012) }\end{array}$ \\
Labuan, Banten & L. erythropterus & 0.00005L2.8989 & $\begin{array}{l}\text { Imbalang A. } \\
(2013)\end{array}$ \\
\hline
\end{tabular}

Tabel 3. Lm ikan kakap merah di beberapa daerah

\begin{tabular}{llll}
\hline \multicolumn{1}{c}{ Area/ Perairan } & \multicolumn{1}{c}{ Lutjanus spp. } & Lm & Penulis/ Sumber \\
\hline Laut Timor dan Arafura & L.malabaricus & $42 \mathrm{~cm}$ & $\begin{array}{l}\text { Sadhotomo, B \& } \\
\text { Suprapto (2013) }\end{array}$ \\
Kamiali - Papau N Guinea & L.russelli & $28 \mathrm{~cm}$ & $\begin{array}{l}\text { Longenecker, K. et.al. } \\
(2011)\end{array}$ \\
Teluk Persia & L. johnii & $44 \mathrm{~cm}$ & Kamalei E, (2001) \\
\hline
\end{tabular}




\section{Pembahasan potensi sumberdaya ikan}

Upaya penangkapan dengan menggunakan jaring gillnet, arad dan bubu di fishing ground kakap merah perlu dikurang secara bertahap untuk dapat mengoptimumkan hasil tangkapan, maka sebagai contoh dilakukan pengurangan/ penghapusan penggunaan jaring arad, karena alat tangkap tersebut merupakan alat tangkap yang tidak ramah lingkungan dan dilarang penggunaannya. Tetapi untuk kepentingan pengelolaan, penggunaan alat tangkap pancing perlu ditingkatkan atau ditambah dengan fishing ground baru yang lebih jauh dan lebih luas dengan ukuran mata pancing yang lebih besar dari No.10 agar lebih selektif, sehingga ukuran ikan pertama kali tertangkap lebih besar dari ukuran ikan pertama kali matang gonad (Lc $>\mathrm{Lm})$.

\section{Pembahasan aspek lingkungan perairan}

Menurut Wyrtki (1961) salinitas perairan Laut Jawa pada musim barat sebesar 32 \%o, dan menurut Potier (1988) dalam Chodriyah (2009) perairan Laut Jawa pada musim barat sebesar $28{ }^{\circ} \mathrm{C}$. Berdasarkan hasil penelitian Pusat Penelitian dan Pengembangan Perikanan (1991) ikan kakap merah umumnya tertangkap pada kedalaman dasar antara 40-50 m dengan substrat sedikit karang dan salinitas 30-33 $\%$ o serta suhu antara $5-32{ }^{\circ} \mathrm{C}$.

Berdasarkan parameter lingkungan tersebut, dapat diinformasikan bahwa salintas dan suhu di perairan utara Cirebon tidak terdapat perubahan yang signifikan dan perairan tersebut merupakan daerah penangkapan ikan yang cocok bagi usaha penangkapan ikan kakap merah.

\section{Pembahasan aspek sosial}

Sehubungan dengan hal tersebut, telah terjadi perubahan sosial di sebagian masyarakat, dari yang cenderung eksplotatif dengan menggunakan alat tangkap yang tidak ramah lingkungan seperti arad menjadi pendekatan yang memperhatikan keberlanjutan sumberdaya ikan dengan menggunakan alat tangkap yang lebih ramah lingkungan berupa pancing dengan alat bantu pengumpul ikan berupa rumpon dasar. Selain itu penempatan rumpon juga bermanfaat sebagai pemulihan habitat suberdaya ikan yang telah rusak sebelumnya dengan membuat habitat baru disamping aspek pemanfaatan dari sumberdaya perikanan tersebut.

\section{Pengelolaan sumberdaya ikan kakap merah}

Berdasarkan hasil penelitian, teknik pengelolaan sumberdaya ikan kakap merah yang berkelanjutan dapat dilakukan dengan pendekatan sebagai berikut:

Pengaturan terhadap ukuran mata pancing, fishing ground dan pembatasan ukuran ikan yang boleh ditangkap

Ikan kakap merah yang tertangkap dengan alat tangkap pancing dengan ukuran mata pancing No 8-10 umumnya tertangkap pada selang kelas panjang 255-313 mm. Berdasarkan analisa hubungan panjangberat diperoleh informasi pola pertumbuhan yang bersifat allometrik negatif, sehingga diperkirakan ikan kakap merah yang tertangkap tersebut pada umumnya masih muda yang sedang giat-giatnya tumbuh berkembang dewasa.

Selain itu berdasarkan analisa panjang pertama kali tertangkap diperoleh informasi Lc $<$ Lm yang artinya ikan kakap merah di perairan utara Cirebon secara umum tertangkap sebelum melakukan pemijahan. Jika kondisi penangkapan tersebut tetap berlanjut maka rekrutmen ikan kakap akan terancam. Sehubungan dengan hal tersebut untuk kepentingan pengelolaan sumberdaya ikan perlu pengaturan ukuran mata pancing ke arah ukuran yang lebih besar dari No. 10 agar lebih selektif dan lebih dewasa, serta diarahkan pada fishing ground baru yang lebih luas dan jauh sekitar terumbu karang dengan harapan ikan kakap merah yang tertangkap akan lebih besar atau sudah melakukan pemijahan atau matang gonad.

Pengaturan jumlah armada penangkapan dan jenis alat tangkapan ikan

Ikan kakap merah di perairan utara Cirebon tertangkap dengan alat penangkap ikan jenis arad, gillnet, pancing dan bubu. Berdasarkan hasil analisa tingkat pemanfaatan, sumberdaya ikan kakap merah di perairan utara Cirebon pada tahun 2008-2012 cenderung over fishing.

Sehubungan dengan hal tersebut, maka upaya penangkapan dengan menggunakan gillnet dan bubu di fishing ground ikan kakap merah perlu dikurang secara bertahap, sedangkan upaya penangkapan dengan 
jaring arad perlu dihilangkan sesuai dengan Peraturan Menteri Kelautan dan Perikanan Nomor: PER.02/MEN/2011. Tetapi untuk kepentingan pengelolaan, penggunaan alat tangkap pancing perlu ditingkatkan dan dikembangkan jumlahnya dengan menggunakan ukuran mata pancing yang lebih besar.

Pengelolaan lingkungan melalui rumpon dasar sebagai terumbu karang buatan

Berdasarkan parameter lingkungan dapat diinformasikan bahwa perairan utara Cirebon merupakan fishing ground yang subur dan cocok bagi usaha penangkapan ikan kakap merah. Rusaknya habit sumberdaya ikan di perairan pantai akibat pengoperasian alat tangkap yang tidak ramah lingkungan seperti arad. Pemulihannya dapat dilakukan dengan penempatan rumpon dasar yang dapat berfungsi sebagaimana terumbu karang buatan atau daerah penangkapan yang pasti sehingga para nelayan tidak bersifat berburu ikan tetapi sudah bersifat menangkap ikan.

\section{Pengaturan regulasi}

Terdapatnya Peraturan Menteri dan kearifan lokal di lapangan sebenarnya sudah sangat baik dan cocok untuk peningkatan perikanan kakap merah secara berkelanjutan. Namun yang lebih penting dari peraturan tersebut adalah penegakan hukum terhadap regulasi pengaturan tingkat upaya penangkapan (effort) dan jenis alat penangkap ikan yang tidak ramah lingkungan seperti arad.

\section{KESIMPULAN DAN SARAN}

\section{Kesimpulan}

Kesimpulan dari penelitian ini yaitu pola pertumbuhan ikan kakap merah di perairan utara Cirebon bersifat allometrik negatif dan sebagian besar ikan kakap merah yang tertangkap dengan alat tangkap pancing dengan ukuran mata pancing No 8-10 belum memijah atau belum dewasa, pemanfaatan sumberdaya ikan kakap merah di perairan utara Cirebon cenderung over fishing karena tingginya tingkat upaya penangkapan di perairan sekitar pantai, dan masih beroperasinya alat tangkap yang tidak ramah lingkungan seperti arad, parameter lingkungan di perairan utara Cirebon tidak terdapat perubahan yang signifikan dan perairan tersebut merupakan fishing ground dan habitat yang cocok bagi usaha penangkapan ikan kakap merah, dan terdapat perubahan sosial di sebagian masyarakat nelayan Cirebon, dari yang cenderung eksploitatif dengan menggunakan alat tangkap yang tidak ramah lingkungan seperti arad menjadi pendekatan yang memperhatikan keberlanjutan sumberdaya ikan dengan menggunakan alat tangkap yang lebih ramah lingkungan berupa pancing dengan alat bantu pengumpul ikan berupa rumpon dasar.

\section{Saran}

1. Arad yang merupakan alat tangkap yang tidak ramah lingkungan seharusnya dihilangkan sesuai dengan Peraturan Menteri Kelautan dan Perikanan Nomor: PER.02/MEN/2011 dan kearifan lokal.

2. Pada umumnya ikan yang tertangkap dengan pancing masih belum memijah atau belum dewasa, maka perlu dikaji dan diatur ukuran mata pancing yang digunakan agar $\mathrm{Lc}>\mathrm{Lm}$.

3. Perlu memperluas fishing ground ketempat yang lebih jauh disekitar perairan terumbu karang untuk dapat menangkap ikan-ikan yang lebih besar yang telah memijah.

\section{DAFTAR PUSTAKA}

Chodriyah U, Wiyono ES. 2011. Fishing ground dynamics of purse seine fisheries in the Java Sea. Indonesian Fisheries Research Journal. 17(1): 2127.

DJamal R, Marzuki S. 1992. Analisis usaha penangkapan ikan kakap merah dan kerapu dengan pancing prawe, jaring nylon, pancing ulur dan bubu. Jurnal Perikanan Laut. (68): 11-25.

Effendie MI. 2006. Biologi Perikanan. Yogyakarta: Yayasan Pustaka Nusanatara.

Gulland JA.1983. Fish Stock Assesment; A Manual of Basic Methode. ChichesterNew York Brisbane Toronto Singapura.

Imbalan A. 2013. Telaah aspek biologi dan aspek perikanan ikan kakap merah yang didaratkan di Pelabuhan Perikanan Pantai (PPP) Labuan, Pandeglang, Banten. FMIPA. Universitas Indonesia.

Isa MM et al. 2012. Length-weight relationships of some important estuarine fish species from merbok 
estuary, Kedah. Journal of Natural Sciences Research.

Kamalei E. 2001. The reproductive study of golden snapper (Lutjnaus johnii) in Hormozgan waters. Iranian Scientific Fisheries Journal. 1 :73-90.

Kementerian Kelautan dan Perikanan. 2011. Keputusan Menteri Kelautan dan Perikanan Nomor KEP.45/MEN/2011 Tentang Estimasi Potensi Sumberdaya Ikan di WPP-NRI.

Kerstan M. 1985. Age, growth, maturity and mortality estimates of horse mackerel (Trachurustrachurus) from The Waters West of Great Britain Farnhamand Ireland in 1984. Archpelago Fishery Wiss. 36(1/2) :115-154.

Kulbicki M. 2005. A general approach to length-weight relationships for new caledonian lagoon fishes. École Pratique des Hautes Études, Université de Perpignan, Avenue de Villeneuve, FRANCE.

Longenecker K. 2011. Reproduction, catch, and size structure of exploited reeffisher at Kamiali wildlife management area, Papua New Guinea. HonoluluHawaii: Bishop Museum Technical
Report.

Martinez F, Andrade. 2003. A comparison of life histories and ecological aspects among snappers (pisces: Lutjanidae). The Department of Oceanography and Coastal Sciences.

O'Neill MF. 2009. Sustaining productivity of tropical red snapper using new monitoring and reference points. The State of Queensland: Department of Employment, Economic Development and Innovation.

Pusat Penelitian dan Pengembangan Perikanan. 1991. Alat dan cara penangkapan ikan di Indonesia. Jakarta: Puslitbang Perikanan

Sadhotom B, Suprapto. 2013. Interaksi Antar Trawl dan Rawai Dasar pada Perikanan Kakap Merah (Lutjanus malabaricus) di Laut Timor dan Arafura. Jakarta: BRPL.

Widodo J, Suadi. 2006. Pengelolaan Sumberdaya Perikanan Laut. Yogyakarta: Seri Perikanan. 